\title{
Scent marking in Eurasian beaver Castor fiber during winter
}

\author{
Frank ROSELL and Frode BERGAN
}

Rosell F. and Bergan F. 2000. Scent marking in Eurasian beaver Castor fiber during winter. Acta Theriologica 45: 281-287.

The Eurasian beaver Castor fiber Linnaeus, 1758 deposit castor fluid (castoreum) and/or anal gland secretion at scent mounds in their territory year round. We investigated the hypothesis that during winter Eurasian beavers may intensify use of scent, in year round ice-free water systems, during the breeding season. This study showed that the median number of scent marks in 7 territories increased significantly in the breeding (January-March 1996), compared to the nonbreeding portion of winter (October-December 1995), which is consistent with our prediction. The median number of scent marks was significantly higher during February, compared to January and March. This may be due to females approaching or being in oestrous in our study area during February. Further studies are, however, needed to clarify how information in scent marks are coded and transmitted during the breeding season.

Institute of Environmental Studies, Department of Arts and Sciences, Telemark College, N-3800 Bø i Telemark, Norway, e-mail: Frank.Rosell@hit.no

Key words: Castor fiber, scent marking, breeding season, Norway

\section{Introduction}

Various functions have been proposed for scent marking in mammals: identification of species, race, group, or individuals; signalling dominance status, reproductive status, or mood; promoting synchronisation of reproductive cycles, attracting members of the opposite sex, defence of a territory, and reassurance (see for example, reviews by Eisenberg and Kleiman 1972, Johnson 1973, Müller-Schwarze 1974, Thiessen and Rice 1976, Brown 1979).

In many mammalian species the frequency of scent marking increases markedly in the breeding season, and particularly during courtship as the female approaches oestrous (eg Johnson 1973, Gorman and Trowbridge 1989, Matochik et al. 1992, Setz and Gaspar 1997). Such increase involves both marking with scent organs (Rasa 1973, Kruuk et al. 1984) and especially marking with urine, which is a potentially rich source of information concerning reproductive state (Macdonald 1979, 1985, Wells and Bekoff 1981). In female mammals, blood titers of estradiol increase during the follicular phase of the oestrous cycle and drop abruptly at ovulation. Oestrogen levels are therefore an accurate indicator of changes in female receptivity (Gorman and Trowbridge 1989). Indeed, gonadal control of scent 
marking is found in many different species (eg Stoddart 1972, Mech and Peters 1977, Macdonald 1979, 1985, Sun et al. 1994). Epple (1974) suggested that sexual odours might help synchronise seasonal breeding (see also Boinski 1992). Odours in this context serve as a kind of self-advertisement, functioning as an olfactory display, and synchronising sexual arousal and patterns of sexual behaviour (see also Houlihan 1989). Epple (1974) also suggests that pregnant Saguinus females monkeys could use scent-marking to strengthen the pair-bond.

Beavers (Castor spp.) are territorial and live in family units (eg Bradt 1938, Aleksiuk 1968, Wilsson 1971, Nolet and Rosell 1994). The basic family unit consists of a monogamous adult pair, young of the year, yearlings and sometimes two-year olds or older (eg Kudrjasov 1973, Bergerud and Miller 1977, Svendsen 1989, Schulte 1993). Eurasian beavers Castor fiber Linnaeus, 1758 deposit castor fluid from the castor sacs and/or anal gland secretion (AGS) at scent mounds inside the territory during the entire year (Rosell et al. 1998). All beavers may deposit scent, but the adult pair, especially the male, is the primary marker (Hodgdon 1978, Svendsen 1980, Buech 1995). The anal gland is a holocrine secretory gland, but the castor sac is only a pocket lined with a layer of nonsecretory epithelium (Svendsen 1978). The castor sac is believed to be used to store a mixture of secondary metabolites from urine, collectively called castoreum (Svendsen 1978).

One of the main functions of scent marking appears to be the maintenance of territorial rights in both the North American C. canadensis Kuhl, 1820 (eg Houlihan 1989, Welsh and Müller-Schwarze 1989, Schulte 1998) and Eurasian beaver (Rosell and Nolet 1997, Rosell and Bergan 1998, Rosell et al. 1998). However, one aspect of beaver scent marking behaviour that has attracted little research is scent marking during the winter season. Presumably this is because the animals are difficult to observe under the cover of ice (see Hodgdon 1978, Bollinger 1980 , Svendsen 1980), or they simply have not been observed during the winter season. In two studies, only a few scent mounds where recorded in two territories (Nitsche 1985a, b, Klenner-Fringes 1992). More definitive research of Eurasian beavers is needed to determine the relationship between winter season and scent marking activity.

We investigated the hypothesis that Eurasian beavers emphasize scent marking behavior during the breeding season in year round, ice-free water systems. We predicted that during winter, the number of scent marks would be significantly higher during the breeding (January-March) than the nonbreeding portion of winter (October-December).

\section{Material and methods}

The study was conducted on a $9.2 \mathrm{~km}$ section of the Bø River in the municipality of $\mathrm{B} \emptyset\left(59^{\circ} 25^{\prime} \mathrm{N}\right.$, $\left.09^{\circ} 03^{\prime} \mathrm{E}\right)$, Telemark County, Norway. The part of the river studied averages $35 \mathrm{~m}$ in width and meanders through a mixed woodland and agricultural countryside dominated by marine and fluvial deposits (Bergan 1996). Vegetation along the river consists mainly of alder (Alnus incana) with lesser 
amounts of willow Salix spp., birch Betula pubescens, aspen Populus tremula, rowan Sorbus aucuparia, Norway spruce Picea abies, and Scots pine Pinus sylvestris. During winter, a hydroelectric power station upstream regulates flow and water temperature, keeping the river ice-free (Rosell et al. 1998). The river has been occupied by beavers since the 1930s (Olstad 1937).

Observations of scent marking activity were recorded biweekly during October-December (nonbreeding portion of winter) 1995, and weekly during January-March 1996 (breeding portion of winter). Each side of the river within the study area was searched, by canoe, for newly used scent mounds. All beaver ascents from the water were examinated closely. Scent mounds are usually small piles of mud and debris, scraped together on land by beavers upon which secretion from the castor sacs and/or anal glands are deposited (eg Wilsson 1971, Rosell and Bergan 1998). A freshly marked scent mound, ie with a scent detectable by the human nose at $2 \mathrm{~cm}$ or more, was termed a "scent mark". This definition also included marks directly on the ground or on tussocks. Minimum distance between two different scent mounds was $10 \mathrm{~cm}$. If a scent mound did not have a smell detectable by the human nose, it was thought to be old and excluded from analysis (see however Bollinger 1980, Schulte 1993). Each scent mark was labelled for recognition, either with a small wooden stake placed $0.5-1 \mathrm{~m}$ behind the mark, or by writing the number on natural objects such as trees. All scent marks found were registered on a 1:5000 map. After each land visit, boots were cleaned in water to minimise transport of scent from one area to another. Whenever possible, marks were smelled from the canoe, ie without actually stepping out (Rosell et al. 1998).

We compared numbers of scent marks observed during the breeding versus nonbreeding portion of winter. The results from this comparison are presented with data based on scent mark registrations biweekly (see Rosell et al. 1998 for further details). The differences in number of scent marks during the breeding portion of winter are based on weekly registrations.

Rosell et al. (1998) recorded 28 beavers in the study area during autumn 1995. Family size varied from 3 to $7(\bar{x}=4 \pm 0.6 \mathrm{SE}, n=7)$. Seventy-one percent were adults ( $\geq 2$-years-old), $22 \%$ were 1-year-olds and $7 \%$ were kits. Only one colony produced young in 1995 (two kits). This low number of kits was probably due to a flood in the end of May to the beginning of June during which many may have drowned inside their lodges. All families, except family 4, had one yearling (Rosell et al. 1998). Territorial borders for each family were as described by Rosell et al. (1998).

Because data do not fit assumptions of distribution and homogeneity of variance for parametric analysis (Sokal and Rohlf 1995), we used nonparametric statistics in accordance with Siegel and Castellan (1988). Nonparametric tests were corrected for ties. Probability values are two-tailed and 5\% was used as the level of significance. Mean and median values are presented with standard errors.

\section{Results}

\section{Characteristics of scent marks and sites}

A total of 678 scent marks ( $\bar{x}=97 \pm 16.2$ per family) were found within 7 territories during January-March in 1996. During 30 November 1995 to 9 March 1996, beavers in this study only made mounds of snow (no mud was collected from the bottom of the river). In this period, the river banks were covered with snow to the water's edge.

\section{Number of scent marks during breeding- and nonbreeding portion of winter}

We found a significant difference in the median number of scent marks between the nonbreeding- and breeding portion of winter (Wilcoxon matched-pairs signed-ranks test: $Z=-2.4, n=7, p=0.018$ ). The median number of scent marks was $72 \pm 9.6$ during the breeding portion of winter and $31 \pm 4.9$ during the nonbreeding portion of winter. 
There was also a significant difference in the median number of scent marks during the breeding portion of winter (Friedman two-way ANOVA: $\chi^{2}=14.0$, $\mathrm{df}=2, p=0.0009$ ), between the months January and February, January and March, and between the months February and March (Wilcoxon matched-pairs signed-ranks test: $Z=-2.4, n=7, p=0.018$ for all comparisons), with February higher than January and March (January: $17 \pm 2.4$, February: $62 \pm 9.2$ and March: $35 \pm 4.9)$.

\section{Discussion}

Beavers in our study area scent-marked significantly more during the breeding (January-March) versus the nonbreeding portion of winter (October-December), This finding is consistent with our prediction. Within the breeding portion of winter, the significantly higher median number of scent marks during February, compared with both January and March, suggests that in our study area females are approaching or in oestrus during February. Indeed, several recordings of blood-red marks on the mounds in our study area during February 1996, 1997 and 1998 (F. Rosell, unpubl.) suggested that oestrous females scent marked during this period. No blood-red marks were recorded during January 1996, 1997, or 1998. Further, the gestation period of Eurasian beaver is considered to last 105-107 days (Wilsson 1971, Djoshkin and Safonow 1972, Doboszyńska and Żurowski 1983), so parturition should then occur from mid-May to the beginning of June. This is consistent with parturition dates for our area (F. Rosell, unpubl.). Brenner (1964) found scent marks only during breeding time (in January-February 1959 and in February 1960) in his study of the North American beaver. His estimated breeding dates corresponded with observations of scent marking in the field.

Svendsen (1980) stated that the adult beaver pair are in contact with each other daily inside the lodge and oestrous cues produced by the female can easily be perceived by the male and need not be spread around to attract a mate (see also Houlihan 1989). However, in some places the adult male and female maintain two or more winter lodges and may be found in separate lodges (F. Rosell and F. Bergan, unpubl., B. Schulte, pers. comm.). Also, during ice-free conditions in winter, Eurasian beavers are active outside the lodge for approximately 12 hours daily (Nolet and Rosell 1994). Because the female is receptive for only about 12 hours during each oestrous cycle (Wilsson 1971), she may need an effective method to advertise her reproductive status even if she mates with her lodge-mate. Females may deposit castoreum [volatiles with low molecular weight (Tang et al. 1993, 1995)] at scent mounds to signal to males that ovulation has occurred and to attract them from a distance. In contrast, AGS [high molecular weight (Grønneberg 1978, Grønneberg and Lie 1984, Sun 1996)] may give detailed information at the individual level and therefore induce mating when at a close-range. However, males are thought to be the primary markers (eg Buech 1995) and they may increase their scent marking activity during the breeding season to keep other males away from 
the territory which contain the receptive female, probably by using both castoreum and AGS.

The results supported our hypothesis that Eurasian beaver emphasize scent marking behavior during the breeding season in year-round, ice-free water systems. The results also supported our prediction that in winter the number of scent marks would be significantly higher during the breeding versus the nonbreeding portion of winter. Further studies are, however, needed to clarify how information in scent marks are coded and transmitted during the breeding season.

Acknowledgements: We thank G. Hartman, J. Heggenes, B. A. Schulte, A. Sliwa and L. Sun for comments on an earlier draft, two anonymous reviewers for comments on the submitted manuscript and H. Parker for valuable discussions. The study was supported financially by the Telemark County Conservation Department, and Telemark College, Norway.

\section{References}

Aleksiuk M. 1968. Scent-mound communication, territoriality, and population regulation in beaver Castor canadensis Kuhl. Journal of Mammalogy 49: 759-762.

Bergan F. 1996. Scent marking behaviour by the Eurasian beaver Castor fiber Linnaeus, 1758 in the Bø River, Telemark. Temporal and spatial distribution during an entire year. Hovedoppgave, Høgskolen i Telemark, institutt for natur- og miljøforvaltning, Bø i Telemark: 1-45. [In Norwegian with English summary]

Bergerud A. T. and Miller D. R. 1977. Population dynamics of Newfoundland beaver. Canadian Journal of Zoology 55: 1480-1492.

Boinski S. 1992. Olfactory communication among Costa Rican squirrel monkeys: a field study. Folia Primatologica 59: 127-236.

Bollinger K. S. 1980. Scent marking behavior of beaver Castor canadensis. M Sc thesis, University of Massachusetts, Amherst: 1-186.

Bradt G. W. 1938. A study of beaver colonies in Michigan. Journal of Mammalogy 19: 139-162.

Brenner F. J. 1964. Reproduction of the beaver in Crawford County, Pennsylvania. The Journal of Wildlife Management 28: 743-747.

Brown R. E. 1979. Mammalian social odors: a critical review. Advances in the Study of Behavior 10: 103-162.

Buech R. R. 1995. Sex difference in behavior of beavers living in near-boreal lake habitat. Canadian Journal of Zoology 73: 2133-2143.

Djoshkin W. W. and Safonow W. G. 1972. Die Biber der alten und neuen Welt. A. Ziemsen Verlag. Wittenberg, Lutherstadt, Germany: 1-168.

Doboszyńska T. and Żurowski W. 1983. Reproduction of the European beaver. Acta Zoologica Fennica 174: 123-126.

Eisenberg J. F. and Kleiman D. G. 1972. Olfactory communication in mammals. National Zoological Park, Smithsonian Institution, Washington, DC: 1-32.

Epple G. 1974. Olfactory communication in South American Primates. Annals New York Academy of Sciences 237: 261-278.

Gorman M. L. and Trowbridge B. J. 1989. The role of odor in the social lives of carnivores. [In: Carnivore behaviour ecology and evolution, New York. J. L. Gittleman, ed]. Cornell University Press, New York: $57-88$.

Grønneberg T. Ø. 1978. Analysis of a wax ester fraction from anal gland secretion of beaver Castor fiber by chemical ionization mass spectrometry. Chemica Scripta 13: 56-58.

Grønneberg T. Ø. and Lie T. 1984. Lipids of the anal gland secretion of beaver Castor fiber. Chemica Scripta 24: 100-103. 
Hodgdon H. E. 1978. Social dynamics and behavior within an unexploited beaver Castor canadensis population. Ph D thesis, University of Massachusetts, Amherst: 1-292.

Houlihan P. W. 1989. Scent mounding by beaver Castor canadensis: Functional and semiochenical aspects. M Sc thesis, State University of New York, College of Environmental Science and Forestry, Syracuse, New York: 1-184.

Johnson R. P. 1973. Scent marking in mammals. Animal Behaviour 21: 521-535.

Klenner-Fringes B. 1992. Revitalization of river banks by the beaver Castor fiber albicus Matschie, 1907 - a research project. [In: Semiaquatische Säugetiere, Halle-Wittenberg. R. Schripfer, M. Stubbe and D. Heidecke, eds]. Wissenschaftliche Beiträge/Martin-Luther-Universität: 141-153.

Kruuk H., Gorman M. and Leitch A. 1984. Scent-marking with the subcaudal gland by the European badger, Meles meles L. Animal Behaviour 32: 899-907.

Kudrjasov V. S. 1973. [Beaver colony composition and the relationship between the two beaver species]. [In: Den 5. allsovjetiske konferansen om bever. T. Jansson, ed]. Statliga naturreservatet i Oka: 82-85. [In Swedish]

Macdonald D. W. 1979. Some observations and field experiments on the urine marking behavicur of the red fox Vulpes vulpes. Zeitschrift für Tierpsychologie 51: 1-22.

Macdonald D. W. 1985. The carnivores: Order Carnivora. [In: Social odours in mammals. R. E. Frown and D. W. Macdonald, eds]. Clarendon Press, Oxford: 619-722.

Matochik J. A., White N. R. and Barfield R. J. 1992. Variations in scent marking and ultrisonic vocalizations by Long-Evans rats across the estrous cycle. Physiological Behaviour 51: 783-736.

Mech L. D. and Peters R. P. 1977. The study of chemical communication in free ranging animals U.S. Fish and Wildlife Service, Central Forest Experiment Station, Folwell Avenue St Paul, MN 5108. Department of Psychology, Fort Lewis College, Durango, Colorado 81301: 321-332.

Müller-Schwarze D. 1974. Olfactory recognition of species, group, individuals and physiological itates among mammals. [In: Pheromones, Amsterdam. M. C. Birch, ed]. North Holland Publishirg Co: 316-326.

Nitsche K. A. 1985a. Reviermarkierung beim Elbebiber Castor fiber albicus. Mitteilunge1 der Zoologischen Gesellschaft Braunau 4: 259-273.

Nitsche K. A. 1985b. Zum Markierungsverhalten des Elbebibers Castor fiber albicus MATSCHIE 1907. Säugetierkunde Information 2: 245-253.

Nolet B. A. and Rosell F. 1994. Territoriality and time budgets in beaver during sequential settlenent. Canadian Journal of Zoology 72: 1227-1237.

Olstad O. 1937. [The distribution of the beaver Castor fiber in Norway]. Nytt magasin for naturvidenskapene 77: 217-273. [In Norwegian]

Rasa O. A. E. 1973. Marking behaviour and its significance in the African dwarf mongoose, Heogale undulata rufula. Zeitschrift für Tierpsychologie 32: 449-488.

Rosell F. and Bergan F. 1998. Free-ranging Eurasian beavers, Castor fiber, deposit anal gland secetion when scent marking. Canadian Field-Naturalist 112: 532-535.

Rosell F., Bergan F. and Parker H. 1998. Scent-marking in the Eurasian beaver Castor fibel as a means of territory defense. Journal of Chemical Ecology 24: 207-219.

Rosell F. and Nolet B. A. 1997. Factors affecting scent-marking behavior in the Eurasian beaver Castor fiber. Journal of Chemical Ecology 23: 673-689.

Schulte B. A. 1993. Chemical communication and ecology of the North American beaver Castor canadensis. Ph D thesis, State University of New York, College of Environmental Sciene and Forestry, Syracuse, New York: 1-194.

Schulte B. A. 1998. Scent marking and responses to male castor fluid by beavers. Jourial of Mammalogy 79: 191-203.

Setz E. Z. F. and Gaspar D. A. 1997. Scent-marking behaviour in free-ranging golden-facel saki monkeys, Pithecia pithecia chrysocephala: sex differences and context. Journal of Zoology, Lindon 241: 603-611.

Siegel S. and Castellan N. J. 1988. Nonparametric statistics for the behavioral sciences. McGrav-Hill, New York: 1-399. 
Sokal R. R. and Rohlf F. J. 1995. Biometry. The principles and practice of statistics in biological research. $3 \mathrm{r}$ edition. W. H. Freeman and Company, New York: 1-887.

Stoddart D. M. 1972. The lateral scent organs of Arvicola terrestris Rodentia: Microtinae. Journal of Zoology, London 166: 49-54.

Sun L. 1996. Chemical kin recognition in the beaver Castor canadensis: behavior, relatedness and information coding. Ph D thesis, State University of New York, College of Environmental Science and Forestry, Syracuse, New York: 1-183.

Sun L., Xiao B. and Dai N. 1994. Scent marking behaviour in the male Chinese water deer. Acta Theriologica 39: 177-184.

Svendsen G. E. 1978. Castor and anal glands of the beaver Castor canadensis. Journal of Mammalogy 59: 618-620.

Svendsen G. E. 1980. Patterns of scent-mounding in a population of beaver Castor canadensis. Journal of Chemical Ecology 6: 133-148.

Svendsen G. E. 1989. Pair formation, duration of pair-bonds, and mate replacement in a population of beaver Castor canadensis. Canadian Journal of Zoology 67: 336-340.

Tang R., Webster F. X. and Müller-Schwarze D. 1993. Phenolic compounds from male castoreum of the North American beaver Castor canadensis. Journal of Chemical Ecology 19: 1491-1500.

Tang R., Webster F. X. and Müller-Schwarze D. 1995. Neutral compounds from male castoreum of North American beaver, Castor canadensis. Journal of Chemical Ecology 21: 1745-1762.

Thiessen D. and Rice M. 1976. Mammalian scent gland marking and social behavior. Psychological Bulletin 83: 505-539.

Wells M. C. and Bekoff M. 1981. An observational study of scent marking in coyotes, Canis latrans. Animal Behaviour 29: 332-350.

Welsh R. G. and Müller-Schwarze D. 1989. Experimental habitat scenting inhibits colonization by beaver, Castor canadensis. Journal of Chemical Ecology 3: 887-893.

Wilsson L. 1971. Observations and experiments on the ethology of the European beaver Castor fiber L. Viltrevy 8: 115-266.

Received 16 November 1998, accepted 16 August 1999. 